\title{
Festschrift to recognise and celebrate Christoph Cremer's contribution to the field of biophysics on the occasion of his 65th birthday
}

\author{
Udo Jochen Birk · Michael Hausmann
}

Received: 24 May 2009/Accepted: 25 May 2009/Published online: 18 June 2009

(C) European Biophysical Societies' Association 2009

This special issue of the European Biophysics Journal is dedicated to Professor Christoph Cremer and is published as a festschrift on the occasion of his 65th birthday in July 2009. His contributions to the field of biophysics (highresolution fluorescence microscopy, flow cytometry, architecture of the cell nucleus) have been a starting point for countless ongoing research activities all over the world. With the span of topics of the articles at hand we do not aspire to give an account of his major findings let alone cover fully the scope of his areas of expertise, but rather to present an excerpt of current research related to his early work in Munich and Freiburg, Germany, and at the Lawrence Livermore National Laboratory, USA, as well as to more recent findings within his ongoing career at Heidelberg and Maine.

"In order for the light to shine so brightly, the darkness must be present."-Sir Francis Bacon.

As expressed by Sir Francis Bacon, Christoph Cremeras a pioneer in the field of fluorescence microscopy-realised and demonstrated early on how microscopic images can benefit from the immensely increased contrast achieved by separating the illumination from the detection light, as featured in fluorescence microscopy. In particular, his contributions to the field of light optical microscopy, always dedicated to understanding the functional architecture of the cell nucleus, have shown how a greatly

This article has been submitted as a contribution to the festschrift entitled "Uncovering cellular sub-structures by light microscopy" in honour of Professor Cremer's 65th birthday.

U. J. Birk ( $₫)$ · M. Hausmann

Kirchhoff-Institut für Physik, Im Neuenheimer Feld 227,

69120 Heidelberg, Germany

e-mail: uspoeri@kip.uni-heidelberg.de improved structural resolution can be accomplished by spectrally selective discrimination of the detected signal.

Until a few years ago, the resolution limit of conventional light microscopy (of about $200 \mathrm{~nm}$ laterally and $600 \mathrm{~nm}$ axially, as realised in confocal laser scanning microscopy, CLSM) based on Ernst Abbe's theory of diffraction, had been thought of as an insurmountable restraint imposed by nature. However, by means of specific fluorescence labelling and separate detection of the emitted signal, Christoph Cremer's group accomplished a structural resolution in terms of distances and sizes in the nanometre range by using various approaches such as spectral precision distance microscopy (SPDM) and spatially modulated illumination (SMI) microscopy. Recently, these techniques could be advanced towards in vivo studies of fluorescently labelled macro-complexes or gene regions, and by means of spectral position determination microscopy, a localisation accuracy and thus an effective optical resolution of about $20 \mathrm{~nm}$ could be achieved.

Together with his brother Thomas, today head of the Institute of Human Genetics and Anthropology, LMU Munich, Christoph Cremer started his work on the elucidation of the functional architecture of the cell nucleus with studies on the influence of ultraviolet (UV) micro-irradiation to analyse the machinery involved in cell replication and cell repair, in particular on the level of DNA. Beginning with these early investigations in Freiburg, which demonstrated that chromosomes occupy only small volumes in a cell nucleus and are not randomly dispersed DNA fibres, he continued to study the arrangement of chromatin, and significantly contributed to the model of chromosome territories and their functionally determined three-dimensional organisation in cell nuclei. In the late 1960s, advancements in the understanding of the cell nucleus urged Christoph Cremer to propose a novel type of microscope capable of 


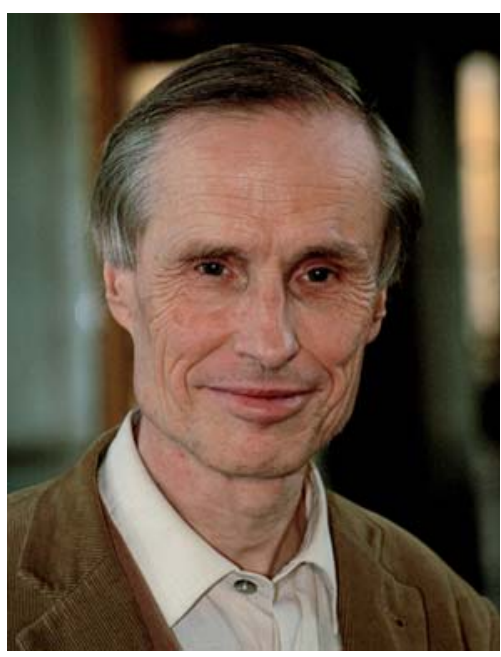

Prof. Christoph Cremer. Photo by Friederike Hentschel

providing highest resolution optical sectioning of cells which carried fluorescent labels attached to specific subcompounds. This type of microscope, the CLSM, is based on the principle of the confocal microscope by Minsky dating back to the 1950s, and is now ubiquitously used in biological and medical laboratories all over the world.

Christoph Cremer studied Physics in Munich, and obtained his first Ph.D. in the field of biophysics and genetics at the University of Freiburg in 1976. From 1980 to 1983 he did pioneering work at the Lawrence Livermore National Laboratory in California in the field of flow cytometry and contributed to one of the first chromosomespecific DNA libraries. In 1983, he became Dr. med. habil. in general human genetics and experimental cytogenetics at the Faculty of Medicine, University of Freiburg, and was then appointed Professor of Applied Optics and Information Processing at the University of Heidelberg. Since 2004 he has been Ordinarius at the Kirchhoff-Institute of Physics, Director of the Cooperation Unit "Biophysics of the Genome Structure" at the Institute of Pharmacy and Molecular Biotechnology (University of Heidelberg) as well as Adjunct Senior Staff Scientist at the Jackson Laboratory, Bar Harbor, Maine.

During Christoph Cremer's professional career, which has spanned some 40 years, he has educated scores of aspiring biophysicists and collaborated with colleagues from all over the globe, making him one of the major figures of present-day far-field microscopy. His activities are reflected in more than 250 scientific articles, tens of patents and innumerable abstracts and have always provided a sturdy bridge connecting the development of novel optical instrumentation - in combination with quantitative image analysis and specific DNA probing techniqueswith the aim of understanding the three-dimensional nuclear architecture on the micro- as well as on the nanoscale and its relevance for genome functioning.

We would like to express our gratitude to all the contributing authors and to the editor Professor Anthony Watts, all of whom have made this festschrift possible in the first place. To Tony Watts and the entire editorial team of the European Biophysics Journal we are indebted for their great support. It has been our greatest pleasure to work with all of you on this project. 